\title{
実験結果に基づく最適レギュレータの設計法*
}

岡田 昌史**.福島 宏明**・杉江 俊治**

\section{LQ Optimal Controller Design Method based on Experimental Data*}

Masafumi OKADA**, Hiroaki Fukushima** and Toshiharu SugIE**

\begin{abstract}
This paper gives an LQ optimal controller design method which is based on the iteration of experiment and controller re-design from the viewpoint of joint design of identification and control. This method provides us a systematic method of changing the weighting matrices to achieve better control performance based on the experimental data. Furthermore, the effectiveness of the proposed method is shown by experiments using an inverted pendulum system.
\end{abstract}

\section{1.はじめに}

これまでに提案されている制御則の多くは主に制御対 象のモデルを用いて, ある評価関数を最適化する補償器 を設計するものであり，これを実機に適用した場合モデ ル化誤差などの影響によって評価関数の值は大きくなり， 閉ループ特性が劣化する場合が少なくない. そこで, 実 際に制御を行う場合には実験の応答を見ながら, 設計者 が評価関数（重み関数など）を試行錯誤的に変更し，こ れを繰り返すといった手順が踏まれる.このことから,こ の手順を系統的に行う設計法が望まれる.

そこで近年, この繰り返しを体系的に行うことを目的 とした, 補償器と同定の結合設計が注目されている1),2). この方法は, 設計された補償器を用いて実験を行い, こ の応答からモデルを同定し, モデルおよび評価関数の更 新を行った後に補償器を再設計するという手順を繰り返 すもので, その方法もいくつか提案され, 有効性も検証 されている3)-8). しかし, これらの方法では補償器の設 計と同定が何度も行われるためその手順は複雑なものと なり, また補償器の次数も大きくなる傾向にあるといった 問題点がある. そのため, 補償器の構造を固定し簡単な アルゴリズムによって補償器のパラメータのみを変更す

\footnotetext{
* 原稿受付 1995 年 7 月 28 日

** 京都大学 工学部 Faculty of Engineering, Kyoto University; Uji, Kyoto 611, JAPAN
}

Key Words: LQ optimal control, iterative design, joint design of identification and control, experimental data, experimental evaluation.
るといった方法も必要と思われる.

一方，有効な制御則の一つに最適レギュレータによる 状態フィードバック制御がある。この方法は設計アルゴリ ズムが容易であって補償器は定数行列となり, その有効性 も広く認められている。しかし，実機に適用するにあたつ ては他の制御則同様に, 試行錯誤的に重み行列を変更し 補償器を再設計しているのが現状である.

そこで本論文では, 最適レギュレータの補償器設計に 扮ける繰り返し作業を体系的に行う一つの方法を提案す る。この方法は実験による応答に基づいて重み行列に変 更を施し, 補償器を再設計する手順を繰り返すことによ り閉ループ特性の改善を図るものである。この方法では 補償器の構造を, 定数行列による状態フィードバックに固 定しており，また，モデルの同定を行わないことから設計 アルゴリズムも容易なものとなっている，さらに，本論文 では提案する方法を倒立振子系に適用し, 実験によって その有効性を検証する。

\section{2. 問題設定}

本論文では, 次式によって表される制御対象 $P$ と状態 フィードバック則からなる実際の制御系

$$
\begin{aligned}
& P:\left\{\begin{array}{l}
\dot{x}_{p}(t)=A_{p} x_{p}(t)+B_{p} u_{p}(t) \\
x_{p}(0)=x_{0}
\end{array}\right. \\
& u_{p}(t)=-K x_{p}(t)
\end{aligned}
$$

を考える.ここで, $A_{p}, B_{p}$ の正確な值は未知であるが, $P$ の近似モデル $P_{m}$ が与えられ, 実際の制御系と同様に 
状態フィードバックによって次のような制御系を構成する.

$$
\begin{aligned}
& P_{m}:\left\{\begin{array}{l}
\dot{x}_{m}(t)=A_{m} x_{m}(t)+B_{m} u_{m}(t) \\
x_{m}(0)=x_{0}
\end{array}\right. \\
& u_{m}(t)=-K x_{m}(t)
\end{aligned}
$$

また， $x_{0}$ は既知であり $x_{p}(t)$ はすべて観測可能であると する.このとき，以下の問題を考える.

【問題】(1) 式の制御対象 $P$ に対し，つぎの評価指標 $J_{p}$

$$
J_{p}:=\int_{0}^{\infty} x_{p}^{\mathrm{T}}(t) Q_{0} x_{p}(t)+u_{p}^{\mathrm{T}}(t) R_{0} u_{p}(t) d t
$$

を最小化する定数状態フィードバック補償器 $K$ を(3) 式 の $P_{m}$ に基づいて設計せよ.ただし， $Q_{0}, R_{0}$ は与えら れているものとする.

ここでは $Q_{0}, R_{0}$ は与えられていることを仮定した 一般に最適レギェレー夕問題では,

(i) モデル $P_{m}$ において, 希望の応答を示すような補 償器を得るためには, 重み行列 $Q_{0}, R_{0}$ をどのよ うに選ぶべきか.

(ii) 制御対象のモデル化誤差が存在する場合, 重み行 列 $Q_{0}, R_{0}$ をどのように変形すれば，制御性能の 劣化を改善できるのか.

という問題がある. 本論文では (i) の $Q_{0}, R_{0}$ はすでに与 えられていることを仮定し, 実験と補償器の繰り返しが 必要となる (ii) の問題に注目し, これを体系的に行う一 つの方法を与えることを目的としている.

\section{3. 設計法}

\section{1 設計の基本方針}

2.の問題は, もし $A_{p}, B_{p}$ が既知であるならば最適レ ギュレー夕問題となり, 補償器 $K$ は直ちに求めることが できる。しかし，ここではこれらが未知であることから つぎのような解法を考える。

【解法】(3) 式の $P_{m}$ に対し, 評価指標

$$
J_{m}:=\int_{0}^{\infty} x_{m}^{\mathrm{T}}(t) Q_{n} x_{m}(t)+u_{m}^{\mathrm{T}}(t) R_{n} u_{m}(t) d t
$$

を最小にする補償器 $K$ が同時に (5) 式を最小化するよう な $\left(Q_{n}, R_{n}\right)$ を求める.

(6)式を最小化する問題は最適レギュレー夕問題となり, 重み行列 $Q_{n}, R_{n}$ によって容易に $K$ を求めることができ る. そこで本設計法では実験結果に基づき, 実験と補償器 設計の繰り返しによって $Q_{n}, R_{n}$ を求めることを行う.

\section{2 設計手順}

つぎに, 設計手順について述べる. 本設計法では以下 の手順によって $Q_{i}, R_{i}$ （i は繰り返しの回数を表す）を 求めていく. なお, 以下の設計手順では $i$ 回目の繰り返
しについての説明であり, 添字 $i$ が繰り返しの回数を表 すものとする. また, $J_{m}, J_{p}$ の構造に対して重み行列お よび補償器を陽に表示する場合に $J_{m}=J_{m}\left(Q_{i}, R_{i}, K_{i}\right)$, $J_{p}=J_{p}\left(Q_{i}, R_{i}, K_{i}\right)$ の表現を用いる.

Step 1 モデル $A_{m}, B_{m}$ と $Q_{i}, R_{i}$ を用いて,

$$
K_{i}=\arg \min _{K} J_{m}\left(Q_{i}, R_{i}\right)
$$

より補償器 $K_{i}$ を設計する.

Step 2 実験およびシミュレーションから得られた応答 $x_{p i}(t), x_{m i}(t), u_{p i}(t), u_{m i}(t)$ をサンプリング タイム $T$ ごとに, 横に並べた行列を次式のよう に定める。

$$
\begin{aligned}
& X_{p i}:=\left[\begin{array}{llll}
x_{p i}(0) & x_{p i}(T) & \cdots & x_{p i}(N T)
\end{array}\right] \\
& X_{m i}:=\left[\begin{array}{llll}
x_{m i}(0) & x_{m i}(T) & \cdots & x_{m i}(N T)
\end{array}\right] \\
& U_{p i}:=\left[\begin{array}{llll}
u_{p i}(0) & u_{p i}(T) & \cdots & u_{p i}(N T)
\end{array}\right] \\
& U_{m i}:=\left[\begin{array}{llll}
u_{m i}(0) & u_{m i}(T) & \cdots & u_{m i}(N T)
\end{array}\right]
\end{aligned}
$$

$\underline{\text { Step } 3}$ 上で定めた $X_{p i}, X_{m i}, U_{p i}, U_{m i}$ より，

$$
\begin{aligned}
& \Delta_{Q_{i}}=\underset{\Delta_{Q}}{\arg \min _{1}}\left\|Q_{0}^{\frac{1}{2}} X_{p i}-\Delta_{Q} Q_{i}^{\frac{1}{2}} X_{m i}\right\| \\
& \Delta_{R_{i}}=\underset{\Delta_{R}}{\arg \min _{2}}\left\|R_{0}^{\frac{1}{2}} U_{p i}-\Delta_{R} R_{i}^{\frac{1}{2}} U_{m i}\right\|
\end{aligned}
$$

となる $\Delta_{Q_{i}}, \Delta_{R_{i}}$ を求める.ただし， $\Delta_{Q_{i}}, \Delta_{R_{i}}$ が正則になることを仮定する。ここで,

$$
Q_{i}^{\frac{T}{2}} Q_{i}^{\frac{1}{2}}=Q_{i}, R_{i}^{\frac{T}{2}} R_{i}^{\frac{1}{2}}=R_{i}
$$

であり, $\|A\|=\operatorname{Tr}\left(A^{\mathrm{T}} A\right)$ である.また $\operatorname{Tr}$ はト レースを意味する。

$\underline{\text { Step } 4} Q_{i+1}, R_{i+1}$ を

$$
\begin{array}{cc}
Q_{i+1}^{\frac{1}{2}}=\Delta_{Q_{i}} Q_{i}^{\frac{1}{2}}, & R_{i+1}^{\frac{1}{2}}=\Delta_{R_{i}} R_{i}^{\frac{1}{2}} \\
Q_{i+1}=Q_{i+1}^{\frac{T}{2}} Q_{i+1}^{\frac{1}{2}}, & R_{i+1}=R_{i+1}^{\frac{\mathrm{T}}{2}} R_{i+1}^{\frac{1}{2}}
\end{array}
$$

とする.

Step 5 添字 $i$ を $i=i+1$ とし, Step 1 に戻り同様の手 順を繰り返す.

ここではStep 1 において (7) 式によって設計した $K_{i}$ が $P$ を安定化可能である程度に物理近似モデル $P_{m}$ が $P$ の特性をよく表現していることを仮定した。また, Step 3 の $\Delta_{Q_{i}}, \Delta_{R_{i}}$ は

$$
\begin{aligned}
& \Delta_{Q_{i}}=Q_{0}^{\frac{1}{2}} X_{p i}\left[Q_{i}^{\frac{1}{2}} X_{m i}\right]^{\dagger} \\
& \Delta_{R_{i}}=R_{0}^{\frac{1}{2}} U_{p i}\left[R_{i}^{\frac{1}{2}} U_{m i}\right]^{\dagger}
\end{aligned}
$$

によって計算される.ここで, [· $]^{\dagger}$ は Moore-Penrose 型 の一般逆行列を表す。 


\section{3 考察}

(A) まず, Step 3 における $\Delta_{Q_{i}}, \Delta_{R_{i}}$ の意味につい て述べる. 今 $i$ 回目の繰り返しにより得られた補償器 $K_{i}$ による閉ループ系を考える。このとき，モデルおよび実 際の制御対象は

$$
\begin{aligned}
& P: \dot{x}_{p i}(t)=\left(A_{p}-B_{p} K_{i}\right) x_{p i}(t) \\
& P_{m}: \dot{x}_{m i}(t)=\left(A_{m}-B_{m} K_{i}\right) x_{m i}(t) \\
& x_{p}(0)=x_{m}(0)=x_{0}
\end{aligned}
$$

と表せる。また, 最適レギュレー夕問題は

$$
j_{m}=\left\|\begin{array}{c}
Q_{i}^{\frac{1}{2}}\left[s I-\left(A_{m}-B_{m} K_{i}\right)\right]^{-1} x_{0} \\
R_{i}^{\frac{1}{2}} K_{i}\left[s I-\left(A_{m}-B_{m} K_{i}\right)\right]^{-1} x_{0}
\end{array}\right\|_{2}
$$

を最小化する補償器を設計するのと等価である。このと き (12) 式は, $N \rightarrow \infty$ とすることで

$$
\begin{gathered}
\| Q_{0}^{\frac{1}{2}}\left[s I-\left(A_{p}-B_{p} K_{i}\right)\right]^{-1} x_{0}- \\
\Delta_{Q_{i}} Q_{i}^{\frac{1}{2}}\left[s I-\left(A_{m}-B_{m} K_{i}\right)\right]^{-1} x_{0} \|_{2}
\end{gathered}
$$

を最小化する $\Delta_{Q_{i}}$ を求めていることに相当する.すな わち, $\Delta_{Q_{i}}$ はモデルによって構成される閉ループ系の伝 達関数 $G_{m}$ と実際の閉ループ系の伝達関数 $G_{p}$ の間の関 係を, 初期値 $x_{0}$ に関して

$$
G_{p} \simeq \Delta_{Q_{i}} G_{m}
$$

と定数行列で近似したものとなる. $\Delta_{R_{i}}$ についても同様 である。

(B)つぎに, 本設計法の結合設計としての意味につい て考察する. (17), (18) 式より, $Q_{0}^{\frac{1}{2}} X_{p i}$ と $\Delta_{Q_{i}} Q_{i}^{\frac{1}{2}} X_{m i}$, $R_{0}^{\frac{1}{2}} U_{p i}$ と $\Delta_{R_{i}} R_{i}^{\frac{1}{2}} U_{m i}$ の間には

$$
\begin{aligned}
& \Xi_{i}:=Q_{0}^{\frac{1}{2}} X_{p i}-\Delta_{Q_{i}} Q_{i}^{\frac{1}{2}} X_{m i} \\
& \Lambda_{i}:=R_{0}^{\frac{1}{2}} U_{p i}-\Delta_{R_{i}} R_{i}^{\frac{1}{2}} U_{m i} \\
& \Xi_{i}\left[Q_{i}^{\frac{1}{2}} X_{m i}\right]^{\dagger}=0, \Lambda_{i}\left[R_{i}^{\frac{1}{2}} U_{m i}\right]^{\dagger}=0
\end{aligned}
$$

の関係がある。また， $Q_{i}^{\frac{1}{2}}, R_{i}^{\frac{1}{2}}$ が正則であることを仮定 すると, (27) 式より $\Xi_{i}, \Lambda_{i}$ は次式を満たす.

$$
\Xi_{i} X_{m i}^{\mathrm{T}}=0, \quad \Lambda_{i} U_{m i}^{\mathrm{T}}=0
$$

ここで, $J_{p}$ の積分要素をサンプリングタイム $T$ で一次 近似すると

$$
\begin{aligned}
J_{p}\left(K_{i}\right) & =\int_{0}^{\infty} x_{p i}^{\mathrm{T}}(t) Q_{0} x_{p i}(t)+u_{p i}^{\mathrm{T}}(t) R_{0} u_{p i}(t) d t \\
& \simeq T \cdot \operatorname{Tr}\left(X_{p i}^{\mathrm{T}} Q_{0} X_{p i}\right)+T \cdot \operatorname{Tr}\left(U_{p i}^{\mathrm{T}} R_{0} U_{p i}\right) \\
& =\hat{J}_{m}\left(Q_{i+1}, R_{i+1}, K_{i}\right)+J_{k}+J_{d}
\end{aligned}
$$

$$
\begin{aligned}
\hat{J}_{m} & \left(Q_{i+1}, R_{i+1}, K_{i}\right) \\
& :=T \cdot \operatorname{Tr}\left(X_{m i}^{\mathrm{T}} Q_{i+1} X_{m i}\right) \\
& +T \cdot \operatorname{Tr}\left(U_{m i}^{\mathrm{T}} R_{i+1} U_{m i}\right) \\
J_{k} & :=T \cdot \operatorname{Tr}\left(\Xi_{i}^{\mathrm{T}} \Xi_{i}\right)+T \cdot \operatorname{Tr}\left(\Lambda_{i}^{\mathrm{T}} \Lambda_{i}\right) \\
J_{d} & :=T \cdot \operatorname{Tr}\left(\Xi_{i}^{\mathrm{T}} \Delta_{Q_{i}} Q_{i}^{\frac{1}{2}} X_{m i}+X_{m i}^{\mathrm{T}} Q_{i}^{\frac{\mathrm{T}}{2}} \Delta_{Q_{i}}^{\mathrm{T}} \Xi_{i}\right) \\
& +T \cdot \operatorname{Tr}\left(\Lambda_{i}^{\mathrm{T}} \Delta_{R_{i}} R_{i}^{\frac{1}{2}} U_{m i}+U_{m i}^{\mathrm{T}} R_{i}^{\frac{\mathrm{T}}{2}} \Delta_{R_{i}}^{\mathrm{T}} \Lambda_{i}\right)
\end{aligned}
$$

となる.ここで, 初等的な関係 $\operatorname{Tr}(A B)=\operatorname{Tr}(B A)$ を用 いると (28) 式より

$$
J_{d}=0
$$

となり，(29) 式は

$$
J_{p}\left(K_{i}\right) \simeq \hat{J}_{m}\left(Q_{i+1}, R_{i+1}, K_{i}\right)+J_{k}
$$

となる.このとき，(12), (13) 式から $J_{k}$ は $\Delta_{Q_{i}}$, $\Delta_{R_{i}}$ によって最小化されており, $\hat{J}_{m}\left(Q_{i+1}, R_{i+1}, K_{i}\right) \simeq$ $J_{m}\left(Q_{i+1}, R_{i+1}, K_{i}\right)$ は次の補償器によって最小化される 部分となる.この考察から, 本設計法は $i$ 回目に得られた 評価指標 $J_{p}\left(K_{i}\right)$ を二つの要素 $\hat{J}_{m}\left(Q_{i+1}, R_{i+1}, K_{i}\right)$ と $J_{k}$ に分解し, $\Delta_{Q_{i}}, \Delta_{R_{i}}$ の同定によって後者を, $(i+1)$ 回目の補償器によって前者を最小化しこれを繰り返す方 法であるといえる。

(C) つぎに，本設計法では設計手順の収束性を保証す ることは困難であるが, 数多くの数值例により収束の可 能性が極めて高いことから, $i$ 回目の繰り返しで収束した ことを仮定し, 収束先がどのようなものとなるのかを考 察する。なお, 補償器が更新されなくなることをもって 収束という表現を用いる。本設計法が収束したときは,

$$
\Delta_{Q_{i}}^{\mathrm{T}} \Delta_{Q_{i}}=I, \Delta_{R_{i}}^{\mathrm{T}} \Delta_{R_{i}}=I
$$

の関係が成り立つ。よって, (34) 式は

$$
J_{p}\left(K_{i}\right) \simeq \hat{J}_{m}\left(Q_{i}, R_{i}, K_{i}\right)+J_{k}
$$

となり, $J_{k}$ は $\Delta_{Q_{i}}, \Delta_{R_{i}}$ の同定によって最小化されてお り, $\hat{J}_{m}\left(Q_{i}, R_{i}, K_{i}\right)$ はすでに補償器 $K_{i}$ によって最小化さ れている.すなわち, $J_{p}\left(K_{i}\right)$ は二つの要素に分解され, それぞれが同定, 補償器設計によって最小化されているこ とが理解できる. また， $J_{k}$ は (12), (13) 式の $\Delta_{Q}, \Delta_{R}$ を 定数行列で近似することの限界の值と考えられる. しか し, 実際には $J_{p}$ の值は最小化されにくい.これは $\Delta_{Q_{i}}$, $\Delta_{R_{i}}$ の同定において $K_{i+1}$ を用いずに $K_{i}$ を用いている こと, 補償器は常に固定されたモデル $P_{m}$ に基づいて設 計されていることにあると考えられる。これにより本設 計法は 2.の問題の近似解であるといえる.

(D) また, 最適レギュレータを実際に用いる場合には, 意味の明確さと設計パラメータの減少を目的として重み 
行列には対角行列が用いられる場合が多い.しかし，本 設計法ではこれ以外の要素も利用しているため, よりよ い性能を持った補償器が設計されることが期待できる.

\section{4. 実験}

つぎに，本設計法を倒立振子系に適用し，実験を行う ことで有効性を検証する.

\section{1 モデル化}

ここでは Fig. 1に示されるような回転型の倒立振子を 制御対象とする.このシステムに対し，入力をモー夕の出 力するトルクとして運動方程式を求め, 振子拉よびア一 ムの回転角とその速度を十分小さいものとして平衡点ま わりで線形近似することで得られる物理モデルは次式の ようになる。

$$
\begin{aligned}
& P_{m}: \dot{x}_{m}(t)=A_{m} x_{m}(t)+B_{m} u_{m}(t) \\
& A_{m}=E^{-1} M, \quad B_{m}=E^{-1}\left[\begin{array}{llll}
0 & 0 & 0 & 1
\end{array}\right]^{\mathrm{T}} \\
& x_{m}=\left[\begin{array}{llll}
\theta & \dot{\theta} & \phi & \dot{\phi}
\end{array}\right]^{\mathrm{T}} \\
& E=\left[\begin{array}{cccc}
1 & 0 & 0 & 0 \\
0 & m l^{2}+I & 0 & m L l \\
0 & 0 & 1 & 0 \\
0 & m L l & 0 & m L^{2}+J
\end{array}\right] \\
& M=\left[\begin{array}{cccc}
0 & 1 & 0 & 0 \\
m g l & -D & 0 & 0 \\
0 & 0 & 0 & 1 \\
0 & 0 & 0 & -D_{m}
\end{array}\right]
\end{aligned}
$$

ただし，パラメータは以下のように定めた

$$
\begin{array}{rlrl}
\theta & : \text { 振子の回転角 } & \phi: \text { アムムの回転角 } \\
m & : \text { 振子の質量 } & l & : \text { 振子の重心高さ } \\
D & : \text { 振子の粘性摩擦 } & L & : \text { アームの長さ } \\
D_{m} & : \text { モー夕の粘性摩擦 } & g & : \text { 重力加速度 } \\
u_{m} & : \text { モータのトルク } & \\
I & : \text { 振子の慣性モーメント } \\
J & : \text { アームの慣性モーメント }
\end{array}
$$

\section{Personal Computer}

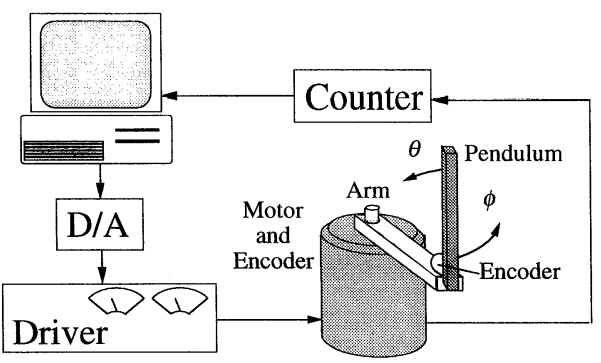

Fig. 1 Inverted pendulum system
(37) 式の導出，パラメータの同定に関しては参考文献 9) に詳しい. (37) (41) 式よりこのシステムは 1 入力で 4 次 のシステムであることがわかる.

\section{2 補償器の設計}

つぎに,このシステムに本設計法を適用する。(37)式 のシステムをモデルとして, 何度かの線形シミュレーショ ンにより， $Q_{0}, R_{0}$ を次式のように定めた。

$$
Q_{0}=\operatorname{diag}[1000,1,1000,1], \quad R_{0}=1
$$

ただし，このシステムは 1 入力系であり $\Delta_{R_{i}}$ はスカラ となるため, 3.3考察 $(\mathbf{A})$ で述べたような伝達関数の近 似を行うのは困難であると考え

$$
R_{i}=R_{0}=1
$$

と，Rについては固定した值を用いた．また，実際の倒立 振子システムにはモデル化誤差を陽に持たせるために根 本から $0.476[\mathrm{~m}]$ のところに質量 $0.09[\mathrm{~kg}]$ の重りを取り 付けた。これにより，本来の振子の長さは $0.485[\mathrm{~m}]$, 質 量は $0.135[\mathrm{~kg}]$ であった（ケース (a) とする) のに対し， 重りにより長さ $0.573[\mathrm{~m}]$, 質量 $0.225[\mathrm{~kg}]$ のものに相当 する（ケース (b) とする). 実験はサンプリングタイム 1

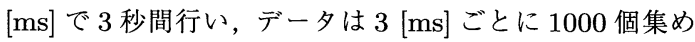
た。また，速度信号は位置信号の差分を用いたが，

$$
\frac{100^{2}}{(s+100)^{2}}
$$

のフィルタを施し，ノイズの影響を抑えた。また初期值は

$$
x_{0}=\left[\begin{array}{llll}
0^{\circ} & 0^{\circ} & 90^{\circ} & 0^{\circ}
\end{array}\right]^{\mathrm{T}}
$$

とした.モデルをケース (a) とし，制御対象をケース (b) として, 本設計法を 5 回繰り返したときの $J_{p}\left(K_{i}\right)$ の推 移を Fig. 2 に，また，はじめの補償器 $K_{1}$ と 5 回目の補 償器 $K_{5}$ を用いた場合の応答（振子とアームの回転角の み）をFig. 3に示す.なお，Fig. 2における実線はモデル をケース (b) としたときの $J_{m}\left(Q_{0}, R_{0}, K\right)$ の最小值であ り，点線はモデル，制御対象共にケース (b) としたとき の $J_{p}$ の值 (実験值) である。この二つが非常に近い值で あることからこのモデルは実際の制御対象をよく近似し ており，真の評価值のほほ最小值を与えていると考えら れる。

\section{3 考察}

この実験結果では $J_{p}$ の值はほほ最小值まで減少し，そ の後は微小な変化になっているのがわかる．このことか ら, 最小化された後は補償器はほとんど更新されなくなっ ていると考えられ, 3.3 (C) で考察した収束性がうかが える.なお，本論文中では省略するが，2慣性共振系にお いても幾つかの数值シミュレーション抢よび実験を行った 


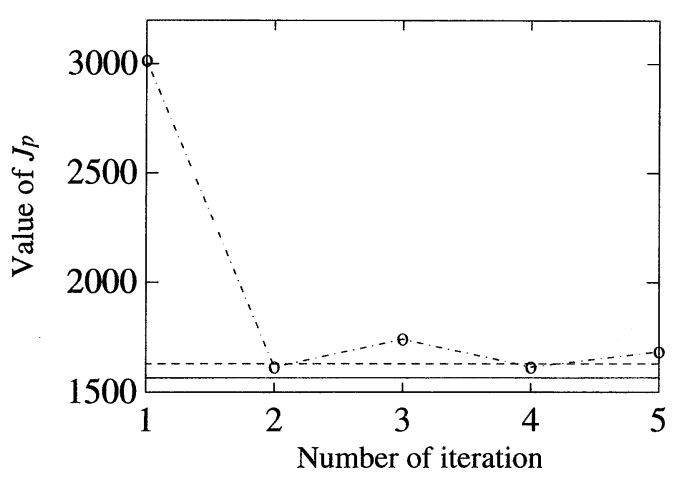

Fig. 2 The value of $J_{p}\left(Q, R, P, K_{i}\right)$

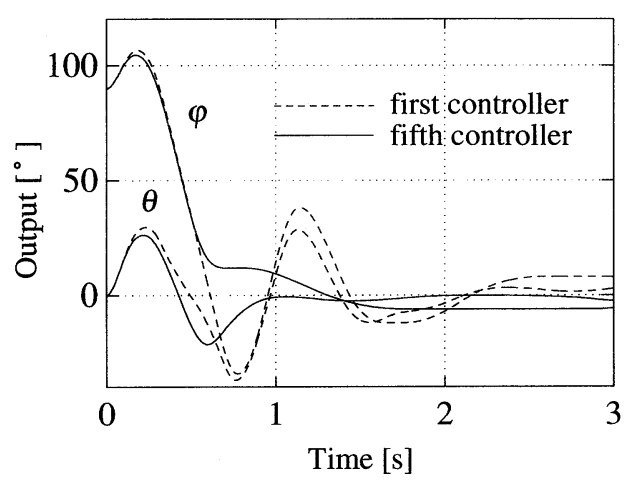

Fig. 3 Responses for initial condition

ところ, $J_{p}$ はある值までは減少し, その後は収束すると いう結果を得ている．収束するまでの繰り返し回数につ いては, 本論文における実験例では 1 回でほぼ収束してい るが, 他の適用例の中には数回の繰り返しを要するもの もあり，一般には繰り返しが必要であると思われる。ま た, 制御対象の選び方 (重りの位置の変更)によっては $J_{p}\left(K_{i}\right)$ の值が減少しない場合もあった。この場合につい て調べた結果, 主にはじめの補償器によって

$$
J_{p}\left(K_{0}\right)<J_{m}\left(K_{0}\right)
$$

が成り立っており， $J_{p}\left(K_{i}\right)$ が繰り返しと共に微小に増加 する傾向にあった。このような場合にはモデルを同定し 直すなどといったことが必要と考えられる。

\section{5. おわりに}

本論文では, 同定と補償器の結合設計の観点から, 補 償器の構造を固定し, 設計アルゴリズムを簡単にするこ とを目的として, 実験結果を利用した最適レギュレータの 設計法を提案し，この設計法に対して考察を加えた。ま た，この設計法を倒立振子系に適用し実験によってその
有効性を検証した。

\section{参考文献}

1) M. Gevers: Towards a joint design of identification and control?, Essays on Control (Trentelman, Willems Eds.), Birkhäuser, pp. 111-151 (1993)

2) R. J. P. Schrama: Accurate identification for control: The necessity of an iterative scheme; IEEE Trans., Vol. AC-37, No. 7, pp. 991-994 (1992)

3) R. J. P. Schrama and P. M. J. Van den Hof: An iterative scheme for identification and control design based on coprime factorization; Proc. of ACC, pp. 2842 2846 (1992)

4) R. G. Hakvoort, R. J. P. Schrama and P. M. J. Van den Hof: Approximate identification in view of LQG feedback design; Proc. of ACC, pp. 2824-2828 (1992)

5) Z. Zang, R. R. Bitmead and M. Gevers: Disturbance rejection: On-line refinement of controllers by closed loop modeling; Proc. of ACC, pp. 2829-2833 (1992)

6) A. G. Partanen and R. R. Bitmead: Two stage iterative identification/controller design and direct experimental controller refinement; Proc. of 32nd CDC, pp. 2833-2838 (1993)

7) H. Hajalmarson, M. Gevers, F. De Bruyne and J. Leblond: Identification for control: closing the loop gives more accurate controllers; Proc. of the 33rd $C D C$, pp. 4150-4155 (1994)

8) 杉江, 岡田: 実験結果との対話的手法によるロバスト補償器 の設計法; システム制御情報学会論文誌, Vol. 8, No. 2, pp. 61-69 (1995)

9) 杉江, 岡田：並列倒立振子システムの $H^{\infty}$ 制御 ; システム 制御情報学会論文誌, Vol. 6, No. 12, pp. 543-551 (1993) 